Poznań Studies in Contemporary Linguistics 45(2), 2009, pp. 261-279

(C) School of English, Adam Mickiewicz University, Poznań, Poland

doi:10.2478/v10010-009-0015-5

\title{
NEW TESTS FOR LANGUAGE MAPPING \\ WITH INTRAOPERATIVE ELECTRICAL STIMULATION \\ OF THE BRAIN TO PRESERVE LANGUAGE IN INDIVIDUALS WITH TUMORS AND EPILEPSY: A PRELIMINARY FOLLOW-UP STUDY
}

\author{
MONIKA POŁCZYŃSKA \\ Adam Mickiewicz University, Poznań \\ plmonik@ifa.amu.edu.pl
}

\begin{abstract}
Intraoperative Electrical Stimulation (IES) of the brain is performed to localise and spare language functional areas before extraction of brain tissue in patients with tumors and epilepsy. The procedure is very precise and highly effective. Yet, it is argued that language tests used during IES are too limited. This article presents new language tests that have a potential of minimising post-operative risk to language function. It is a continuation of a previous study (Połczyńska 2008) and it contains extended versions of earlier presented tests, as well as new tests designed in three sets: (1) Grammar-focused tests for the dominant left hemisphere, (2) Non-dominant righthemisphere tests and (3) Tests for the subcortex. To assure maximum safety and efficiency of the tests before they are used during IES for the first time, it is suggested that they are first used with patients with intractable epilepsy who have a multielectrode subdural grid implanted onto their cortex to trace the source of seizures. The subdural grid gives a chance to carry out an electrical stimulation of those areas of the cortex which are covered with a grid. This type of language mapping is carried out in a ward and is not time-limited.
\end{abstract}

KEYWORDS: Intraoperative Electrical Stimulation (IES); brain; language; right hemisphere; subcortex.

\section{Introduction}

Intraoperative Electrical Stimulation (IES) of the brain is carried out in individuals with epilepsy and tumors prior to the resection of brain tissue to preserve language and motor function in the dominant hemisphere (Huncke et al. 1998; McDermott et al. 2005). The need for language and motor mapping is necessary because cerebral representation of various functions is interindividually variable (e.g. Ojemann et al. 1989; Ojemann 
1991; Momo, Sakai and Sakai 2008). In addition to this, the affected region may potentially re-reorganise to retain its functions (Ebeling et al. 1992; Taylor and Bernstein 1999). Although both language and motor function is tested during IES, for the purpose of this article we will only focus on the language component. According to Ojemann (1991), 91\% of humans have their language functions lateralised in the left hemisphere, $5 \%$ of humans have their language functions represented bilaterally and in the remaining $4 \%$ language is lateralised in the right hemisphere. Although most people seem to have their language functions located in the left hemisphere, Ojemann et al. (1989) showed that there are considerable differences in the exact location of language areas. They conducted an electrical stimulation-mapping study of the left hemisphere in which 117 subjects performed an object-naming test. The study revealed that essential areas were consistently identified only in the left inferior frontal gyrus immediately in front of the facial motor cortex. Interestingly enough, even there, in the traditional Broca's area, stimulation evoked no language changes in $21 \%$ of the subjects. Therefore, IES for language is highly justified before surgical procedures for tumors and epilepsy.

Pre-operative brain imaging (usually, fMRI, less frequently PET) and the intracarotid hemispheric dominance or Wada test are carried out prior to IES to localise areas in the brain that are crucial for language production and perception. Since the correspondence between these pre-operative tests and IES is fairly concordant, the neurosurgeon can be navigated to specific regions of the brain crucial for language that should be further tested with IES (Lehéricy et al. 2000; McDermott et al. 2005).

IES is preceded by sedation of the patient performed in order to remove a portion of the skull. Next, the patient is awakened intraoperatively and a language test is carried out. While the patient is tested, an electrical current is applied to brain regions neighbouring the affected tissue that is supposed to be resected. If language performance is disrupted during electrical current stimulation, it means that a given site of the brain is critical for language and should not be removed. Types of disruption of language production commonly involve: hesitations, slowing of speech, anomia or speech arrest. To avoid a mapping error, IES is applied three times to areas with positive disruption of language performance (Fried et al. 1991; Roux and Trémoulet 2002).

Prior to any neurosurgical procedures including IES, patients with intractable epilepsy have a multielectrode subdural grid implanted onto the surface of the cortex for a few days (Engel et al. 2005). The grid has 3-4 mm diameter electrodes which are embedded $1 \mathrm{~cm}$ apart. This technique is used to trace epilepsy as the grid records the location of seizures in the brain (Crone et al. 1998). Moreover, it also provides the possibility to perform electrical stimulation of the cortex for language as well as motor functions in those areas which are covered with the grid. This type of brain mapping is performed in a hospital ward without any time limitation.

IES considerably diminishes language loss post-operatively (Haglund et al. 1994). However, Połczyńska (2008) points out that language tests used for IES should be expanded to improve post-surgical preservation of language. This paper is a follow-up study to Połczyńska (2008). The author will present extended versions of language tests 
for IES that were proposed in the previous study as well as demonstrate new tests. The tests have not been used with IES and have not been standardised yet and this article is a report from a work in progress. The author will support the necessity of introducing the proposed tests with the current literature.

2. Why should IES language be expanded?

The author proposes three types of new language tests for IES (Połczyńska 2008).

\subsection{Grammar-focused language tests for IES of the dominant left hemisphere}

Considerable research based on lesion studies, electrical stimulation of the brain, as well as numerous non-invasive brain imaging reports show that the Left Hemisphere (LH) is responsible for processing most linguistic information, i.e. phonology, syntax, morphology, semantics, articulation, and a linguistic aspect of prosody (carrying out lexical stress) ${ }^{1}$ (Benson 1979; Larsen et al. 1978; Van Lancker 1980; Wise et al. 1991; Friedmann and Grodzinsky 1997; Chantraine et al. 1998; Arabatzi and Edwards 2002; Marcus et al.2003; Musso et al. 2003; Pouratian et al. 2003; Stark et al. 2006; Love et. al 2008). For example, Fried et al. (1981) demonstrated that electrical stimulation of the left cortex induced disruption in an object naming task in the premotor and motor cortex areas and posterior regions surrounding the Sylvian fissure. A recent study by Davis et al. (2008) shows that Broca's area, which is located in the left hemisphere, has a crucial role in producing and understanding sentences which are syntactically complex. The authors presented a case of a patient with hyperacute stroke. The patient had selective hypoperfusion in his Broca's area with a small infarct (i.e. tissue that is dead because it has been deprived of a blood supply). The patient had problems with: producing grammatical sentences, spelling, speech motor planning and articulation, and some aspects of semantics. When blood flow was restored in the patient's Broca's area, an immediate recovery of language followed and the impaired language functions were restored.

\subsection{IES language tests for the non-dominant right-hemisphere}

The role of the Right Hemisphere (RH) appears to be neglected in all IES research. However, RH is important for cognitive function, including language. Huglings-Jackson

\footnotetext{
${ }^{1}$ It should be mentioned that lesion and brain stimulation studies are of the highest relevance to this paper. This is because this type of data can account for a given language function with a higher level of precision and certainty. As far as non-invasive brain imagine methods (such as fMRI) are concerned, certain regions of the brain may be visible on an imaging scan as being involved in a given cognitive task, yet they are not critical for performing this task (Steven Small, p.c.). For this reason, the author of this article will mainly refer to lesion and brain stimulation studies, although non-imaging studies will also be mentioned.
} 
(1878-1879) noted that individuals with severe aphasia are still able to communicate through prosody, although their language and speech is heavily impoverished. Yet, it was only one century later, in the 1970s, that formal studies on the role of RH in language function began (Heilman et al. 1975) and it was soon accepted that Right Hemisphere Damage (RHD) causes aprosodia (i.e., impairment of prosody), just as Left Hemisphere Damage (LHD) leads to aphasia (Ross 1981). Recent findings by Ross and Monnot (2008: 51) confirm those of numerous earlier studies (e.g. Van Lancker 1980; Ross et al. 1997; Baum and Pell 1999; Dogil 2003; Dara and Pell 2006; Stark et al. 2006) that "affective prosody is a dominant and lateralised function of the right hemisphere".

Sheibel et al. (1985: 72) point out that in the first year of life, RH has a greater dendritic length of lower-order branches which suggests that "portions of the right cortex may 'lead' the left" in the course of this early period of human development. This finding is in line with an observation by Paradis $(1994,2004)$ that during the initial years of mother tongue acquisition, monolingual children rely on pragmatic processing which is stored in $\mathrm{RH}$ to derive an interpretation for $\mathrm{L} 1$ utterances. This is because they have not yet fully developed automatic linguistic competence. Similarly, Curtiss and Shaeffer (2005) argue that RH is crucial in the earliest stages of language acquisition. Curtiss (p.c.) hypothesises that children break the code of language (i.e. learn to recognise words) through prosodic cues processed in $\mathrm{RH}$.

Adult RHD patients commonly have preserved syntax and phonology, while their lexical processing and verbal communication may be impoverished. Thus, they suffer from impairment of non-literal speech which includes metaphors, irony, humour, discourse and indirect speech acts (Chantraine et al. 1998; Shamay-Tsoory et al. 2005; Cutica et al. 2006). RHD patients also exhibit poor inferential abilities and impaired social functioning and reasoning (Cutica et al. 2006). More specifically, Fournier et al. (2008) recently examined two patients 30 years post-surgically who underwent total anatomic hemispherectomy: one subject underwent right-hemispherectomy and the other one lefthemispherectomy. The subject after right-hemispherectomy suffered from severe impoverishment in identifying negative emotions, had difficulties in processing lies and sarcasm and found it difficult to mentalise intentions of others (the ability commonly termed Theory of Mind). Conversely, the subject with left-hemispherectomy had only mild problems with identifying emotional expressions of anger and disgust and was otherwise highly skilled interpersonally. On the other hand, he had a severe language impairment. Similarly, a number of studies (e.g. Stuss et al. 2001; Tomkins et al. 2006) shows that RHD leads to problems with Theory of Mind.

A body of research indicates that, in addition to being involved in social cognition, although LH has a predominant role in processing lexicon, a complete semantic processing of words can only take place through joint hemispheric processing (Weems and Zaidel 2005; Monetta et al. 2006). Recent studies show that RH recruits a broader semantic field of words. RH appears to be involved in processing unfamiliar sentences that contain distant semantic relationships, such as ambiguous words and alternate 
meanings of metaphors (Beeman 1998; Kacinik and Chiarello 2007; Mashal et al. 2007; Schmidt and et al. 2007). Finally, Fried et al. (1991) showed that just as IES of the left supplementary motor cortex, IES of this region in RH leads to speech arrest, slowing of speech and vocalisations.

In spite of the fact that RH is critical for so many language functions, it is typically neglected in all of IES research. This is most probably caused by the fact that the nature of deficits following RHD is generally more subtle. Language impairments caused by RHD are more difficult to diagnose in clinical settings and they frequently become more evident in the patient's home environment.

It should be mentioned that the above mentioned functions processed by the $\mathrm{RH}$ may also be mediated by other brain regions (e.g. affect is subserved not only by the RH but also by the limbic basal ganglia and frontal lobe mechanisms (e.g. ShamayTsoory et al. 2005; Shamay-Tsoory et al. 2004). However, without a properly functioning RH, some functions can me impaired or even lost. Therefore, to preserve all the language functions presented above, Połczyńska (2008) postulates that a new separate set of tests should be designed for IES of the RH.

\subsection{Language tests for IES of the subcortex}

Mapping of the deeper structures of the brain is carried out infrequently, while numerous studies show that structures of the subcortex, e.g. the thalamus, caudate nucleus (Fabbro et al. 1997), or subcallosal fasciculus (Duffau et al. 2002), participate in (1) comprehension, (2) lexical selection, (3) language planning, (4) initiation, (5) articulation, and (5) production (including prosody) (Cappa and Vallar 1992; Crosson 1992; Van Lancker Sidtis et al. 2006). Moreover, language in the brain is subserved by a mosaic of networks of neurons. These networks comprise the cortex, the subcortex and reciprocal connections between these two parts of the brain forming the so-called loops (i.e. circuits) which account for language (Damasio 1994). The connections are language pathways that have a form of fibres. Because fMRI and PET have little sensitivity for the subcortex, (Hirsch et al. 2000), language mapping of this part of the brain is the only way to identify and spare functional subcortical structures involved in language as well as language tracts than run through the white matter (Vinas et al 1997; Duffau et al. 2003; Bello et al. 2006).

\section{New IES language tests}

Two native English speakers were tested with the new IES language tests to assess if instructions for the tests were comprehensive and if examples used in all the tasks were not too difficult. The subjects were males, aged 44 and 61. Based on the results obtained with the subjects, the most difficult and problematic examples were removed from the 
IES tests. Prior to an implementation of the new IES test in the operating room, a control group of 30 healthy native speakers of English will be tested in order to standarise the tests.

\subsection{Grammar-focused language tests for IES of the dominant left hemisphere}

Language tests used during IES typically involve a task of naming objects (Pouratian 2003), counting or - if the tissue to be resected is situated in the occipital lobe-reading (McDermott et al. 2005). However, being limited to lexical search and producing sequences of ensuing numbers (which are automatised), these tests fail to account for grammar, i.e. morphological and syntactic structures of language.

Hence, Połczyńska (2008) proposes adding a set of grammatical tests for IES that will be adapted to the stimulation with the electrical current lasting five seconds. It is suggested that the tests be easy since patients undergoing IES may naturally feel anxious about being in the operating room, to the extent that for some patients the procedure may turn out to be impossible (Mc Dermott et al. 2005) and they can quickly become fatigued (Berger and Rostomily 1997). Below are several proposed grammar tests which are a follow-up of Połczyńska (2008).

(1) IES Grammar Test 1: Tenses, questions and negations.

The patient is asked to make an interrogative form and a negation of presented sentences (see Table 1). Questions and negations are going to be tested separately - each within a separate five-second stimulation trial, which gives the total of 30 tokens. This is a simple test investigating complex grammatical operations, such as an ability to use proper tenses, produce questions and negations and inflect verbs.

(2) IES Grammar Test 2: Inflections.

The patient completes an utterance in the following way:

Examiner: I go. He ...

The patient: goes.

Examiner: Jane doesn 't play the guitar. They ...

The patient: don't play the guitar.

All the 20 tokens and expected responses to the tokens are presented in Table 2. The test is designed in such a way that each response fits into the five-second-stimulation of the electrical current. 
Table1. IES Grammar Test 1: Tenses, questions and negations. The patient is asked to make an interrogative form and a negation of the presented sentences. Questions and negations are tested separately - each within a separate five-second stimulation trial, which give a total of 30 tokens.

\begin{tabular}{|c|c|c|}
\hline Sentence & Question & Negation \\
\hline \multirow[t]{2}{*}{ 1. They go to school. } & Do they go to school? & They don't go to school. \\
\hline & Are they going to school? & They don't want to go to school. \\
\hline \multirow[t]{3}{*}{ 2. I am reading a book. } & Am I reading a book? & I'm not reading a book. \\
\hline & Should I read that book? & I don't want to read that book. \\
\hline & Would you read this book? & \\
\hline \multirow[t]{3}{*}{ 3. We will dance. } & Will we dance? & We won't dance. \\
\hline & Should w dance & We don't want to dance. \\
\hline & Would we dance? & We don't like to dance. \\
\hline \multirow[t]{3}{*}{ 4. They have been working hard. } & Have they been working hard? & They haven't been working hard. \\
\hline & Should they be working hard? & They don't want to work hard. \\
\hline & & They are unwilling to work hard. \\
\hline \multirow[t]{4}{*}{ 5. You should apologise to her? } & Should you apologise to her? & You shouldn't apologise to her. \\
\hline & Should I apologise to her? & I will not apologise to her. \\
\hline & Would you apologise to her? & I am not going to apologise to her. \\
\hline & & You can't make me apologise to her. \\
\hline \multirow[t]{2}{*}{ 6. Jim likes to swim. } & Does Jim like to swim? & Jim doesn't like to swim. \\
\hline & Do you think Jim likes to swim? & Jim won't swim. \\
\hline \multirow[t]{3}{*}{ 7. I did my homework. } & Did I do my homework? & I didn't do my homework. \\
\hline & Should I do my homework. & Ididn't like my homework \\
\hline & Did you do your homework? & \\
\hline \multirow[t]{2}{*}{ 8. We are thinking about it. } & Are we thinking about it? & We aren't thinking about it. \\
\hline & Are we going to think about it? & We aren't going to think about it. \\
\hline \multirow[t]{3}{*}{ 9. They would help them. } & Would they help them? & They wouldn't help them. \\
\hline & Will they help them? & They shouldn't help them. \\
\hline & Are they going to help them? & \\
\hline \multirow[t]{3}{*}{ 10. She will play the piano. } & Will she play the piano? & She won't play the piano. \\
\hline & Does she play the piano? & She doesn't like the piano \\
\hline & Is she going to play the piano? & \\
\hline \multirow[t]{3}{*}{ 11. You are friendly. } & Are you friendly? & You aren't friendly. \\
\hline & I am friendly? & \\
\hline & Do you think I am friendly? & \\
\hline \multirow[t]{2}{*}{ 12. She has been smiling a lot. } & Has she been smiling a lot? & She haven't been smiling a lot. \\
\hline & Do you want her to smile a lot? & She's been frowning a lot. \\
\hline \multirow[t]{2}{*}{ 13. He is going to sell his car. } & Is he going to sell his car? & He isn't going to sell his car. \\
\hline & Does he want sell his car? & He doesn't want to sell his car. \\
\hline \multirow[t]{2}{*}{ 14. We are going to win. } & Are we going to win? & We aren't going to win. \\
\hline & & We can't win. \\
\hline \multirow[t]{2}{*}{ 15. They were driving all night. } & Were they driving all night? & They weren't driving all night. \\
\hline & Did they drive all night? & \\
\hline
\end{tabular}


Table 2. IES Grammar Test 2: Inflections. The patient completes a token by providing an inflected form. The test is designed in such a way that each response fits into the five-secondstimulation of the electrical current.

\begin{tabular}{ll}
\hline \multicolumn{1}{c}{ Token } & Response \\
\hline $\begin{array}{l}\text { 1. I go. He... } \\
\text { 2. Jane doesn't play the guitar. They ... }\end{array}$ & He goes. \\
3. They aren't watching TV. I ... & I'm not watching TV. \\
4. We can use the Internet. You .... & You can use the Internet. \\
5. I wanted to be here. They ... & They wanted to be here. \\
6. You run fast. Jack ... & Jack runs fast. \\
7. We didn't forget. You ... & You didn't forget. \\
8. You're smoking too much. I ... & I'm smoking too much. \\
9. We were busy. They ... & They were busy. \\
10. I don't agree. Rita ... & Rita doesn't agree. \\
11. They aren't going. I ... & I'm not going. \\
12. He's smart. We ... & We're smart. \\
13. You were surprised. He ... & He was surprised. \\
14. We should pay. You ... & You should pay. \\
15. Tom wasn't absent. They ... & They weren't absent. \\
16. I have a brother. Pam .... & Pam has a brother. \\
17. They won't come. We ... & We won't come. \\
18. You weren't home. I ... & I wasn't home. \\
19. We can type well. She ... & She can type well. \\
20. Sam was calling the police. You ... & You were calling the police. \\
\hline
\end{tabular}

(3) IES Grammar Test 3: Regular and irregular plural forms.

The test investigates both regular and irregular plural forms of concrete nouns (25 tokens). The patient is presented with two pictures, e.g., one picture shows a pen and another picture shows two pens (see Figure 1). The patient is asked to name the first picture and then the second picture, providing a plural form of the presented nouns. A fivesecond-stimulation of the electrical current is going to be applied for each picture individually. The remaining tokens for the test are: sheep-sheep, car-cars, child-children, house-houses, book-books, ox-oxen, phone-phones, fish-fish, ring-rings, tree-trees, apple-apples, thief-thieves, salmon-salmon, fox-foxes, tweezers-tweezers, chairchairs, woman-women, tooth-teeth, spoon-spoons, leaf-leaves, deer-deer, shortsshorts, ice-cream-ice-creams, scissors-scissors. 

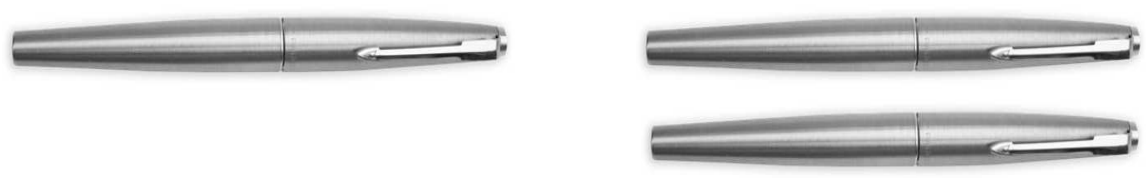

Figure 1. IES Grammar Test 3: Regular and irregular plural forms. The patient is presented with two pictures, e.g. one picture shows a pen (left) and the other picture shows two pens (right). The patient is asked to name the first picture and then the second picture, providing a plural form of the presented nouns. A five-second-stimulation of the electrical current is going to be applied for each picture individually.

\section{(4) IES Grammar Test 4: Spontaneous speech.}

A spontaneous speech test is sometimes used during IES. It is suggested that this type of test is expanded and used more frequently. An extended spontaneous speech task may be very informative during IES because it provides complex information about the patient's production and comprehension abilities.

It is expected that the grammatical set of IES language tests will be more informative because grammatical processing (morphological and syntactic processing and a selection of proper tenses) requires more cognitive effort than a lexical search performed during the object-naming task. However, the element of lexical search is still included in the grammatical tests since the tests require the use of one's lexicon as well.

Połczyńska (2008) argues that the new IES language tests should be introduced gradually. The proposed target ratio of the new tests to the existing ones should reach $60 \%$ (or perhaps $70 \%$ ) for the new tests and $40-30 \%$ for the existing tests.

\subsection{IES language tests for the non-dominant right hemisphere}

A separate set of tests should be designed for IES of RH. Two types of tests are proposed: (1) tests investigating alternative meanings of words and broader semantic relationships, (2) affective prosody tests. All the tests are optimised to fit the five-secondstimulation of the electrical current.

\subsubsection{IES semantic-metaphorical tests}

\section{(1) Test on metaphorical expressions.}

The patient hears a sentence I have butterflies in my stomach and is presented with 3 images (butterflies, a nervous woman, a stomach with butterflies) and is instructed to 

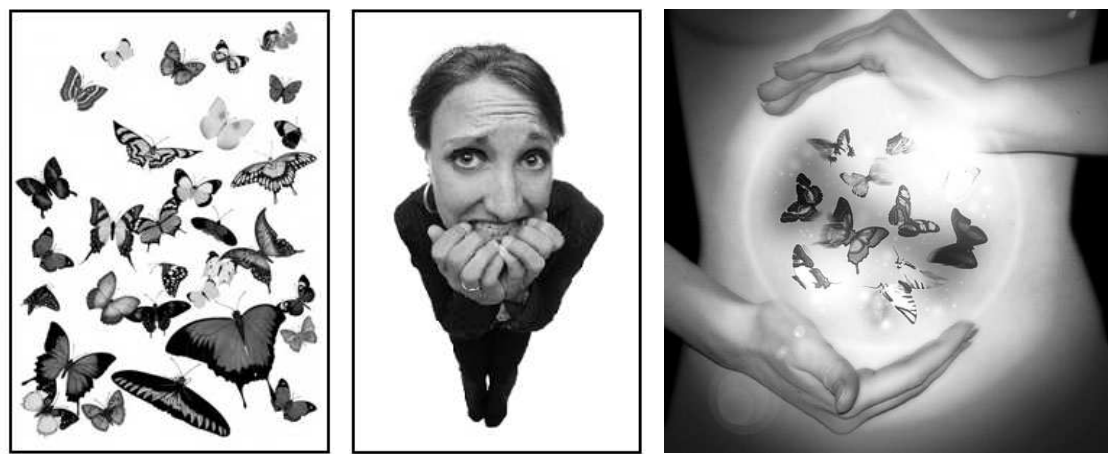

Figure 2. Test on metaphorical expressions. The patient hears a sentence I have butterflies in my stomach and is presented with 3 images: (1) butterflies, (2) a nervous woman and (3) a stomach with butterflies. The patient is instructed to choose a picture corresponding to a metaphorical meaning of the sentence.

choose a picture corresponding to a metaphorical sense of the sentence (see Figure 2). The remaining tokens are presented in Table 3.

\section{(2) Distant semantic relationships test A.}

The aim of the test is to verify a broader semantic field of words. This is a multiplechoice test in which the patient selects a lexical item which does not match/matches the least the remaining three items (see Table 4). The test has been designed in such a way that even the least matching item can still to some extent be related to the remaining items. For instance, football, hockey and basketball are all disciplines of sport which require $a$ coach, hence the word is semantically related to these disciplines. However, given a choice of the four words: football, hockey, coach and basketball, an individual with a normally functioning RH should choose coach as the least matching item. Table 5 contains more examples of the test.

\section{(3) Distant semantic relationships test $B$.}

The patient is asked to choose a metaphorical synonym of a word, e.g.: a sharp bend is (a) cat's eye (b) dogleg (c) sheep's fur (the correct answer is b).

\subsubsection{IES affective prosody tests}

\section{(1) Affective prosody test 1}

The test checks patient's perception of emotional prosody. The patient is shown a picture of a face showing some emotional state (e.g., surprise, boredom) and will hear a 
Table 3. Test on metaphorical expressions. The test compromises ten sentences with metaphors and three images for each sentence. The patient is to choose an imagine corresponding to a metaphorical meaning of the sentence.

\begin{tabular}{|c|c|c|c|}
\hline & Metaphorical sentence & 3 images & Answer \\
\hline & I have butterflies in my stomach & $\begin{array}{l}\text { 1. Butterflies } \\
\text { 2. A nervous woman } \\
\text { 3. A stomach with butterflies }\end{array}$ & 2 \\
\hline & This woman is a star & $\begin{array}{l}\text { 1. A photo of an unknown woman } \\
\text { 2. A star } \\
\text { 3. A photo of a world-famous celebrity }\end{array}$ & 3 \\
\hline & I paid through the nose & $\begin{array}{l}\text { 1. A nose } \\
\text { 2. A lollipop and a } \$ 100 \text { banknote } \\
\text { 3. A } \$ 1 \text { banknote }\end{array}$ & 2 \\
\hline & Maria has a sunny face. & $\begin{array}{l}\text { 1. A face of a happy woman } \\
\text { 2. The sun } \\
\text { 3. A neutral face of a woman }\end{array}$ & 1 \\
\hline & Kate is feeling as light as a feather. & $\begin{array}{l}\text { 1. A feather } \\
\text { 2. A light product (yoghurt) } \\
\text { 3. A jumping woman }\end{array}$ & 3 \\
\hline & We had a stormy discussion. & $\begin{array}{l}\text { 1. Two people arguing } \\
\text { 2. A storm } \\
\text { 3. Two smiling people }\end{array}$ & 1 \\
\hline & Jack has cauliflower ears. & $\begin{array}{l}\text { 1. A man with ears of an average size } \\
\text { 2. A man with big ears } \\
\text { 3. A cauliflower }\end{array}$ & 2 \\
\hline & Tom is feeling under the weather. & $\begin{array}{l}\text { 1. A man working at his desk } \\
\text { 2. Rain } \\
\text { 3. A man in bed looking ill }\end{array}$ & 3 \\
\hline & $\begin{array}{l}\text { The two presidential candidates are } \\
\text { and neck. }\end{array}$ & $\begin{array}{l}\text { K1. Two columns showing equal results } \\
\text { 2. Two necks (long and short) } \\
\text { 3. Two necks (the same length) }\end{array}$ & 1 \\
\hline & I'm as hungry as the wolf & $\begin{array}{l}\text { 1. A wolf } \\
\text { 2. Two wolves fighting } \\
\text { 3. A person eating eagerly }\end{array}$ & 3 \\
\hline
\end{tabular}

sentence. The patient's task is to decide if the sentence has been said in a way that matches the picture. For example, for the picture showing a bored person the sentence is This is so boring! (said in a lively way), while the sentence for "surprise" is I can't believe this! (said with surprise). Thus, some sentences will match their pictures (as in the example with "surprise") and some will not (as in the example with "boredom") based on affective intonation. Table 5 presents all the tokens for the tests. 
Table 4. Distant semantic relationships test $A$. The aim of the test is to verify an ability to access a broader semantic field of words. This is a multiple-choice test in which the patient is to select a lexical item which does not match/matches the least the remaining three items. The test has been designed in such a way that even the least matching item can still be to some extent related to the remaining items.

\begin{tabular}{lllll}
\hline \multicolumn{1}{c}{ A } & B & C & D & Answer \\
\hline 1.football & hockey & coach & basketball & C \\
2.summer & season & winter & spring & B \\
3.love & passion & desire & hate & C \\
4.travel & bike & car & motorbike & A \\
5.lake & ice & sea & ocean & B \\
6.happy & cheerful & joyful & ridiculous & D \\
7.rich & intelligent & money & luxury & B \\
8.Internet & telephone & letter & fax & C \\
9.nervous & clever & brainy & wise & A \\
10.headmaster & teacher & blackboard & student & C \\
\hline
\end{tabular}

Table 5. Affective prosody test 1 . The test checks patient's perception of emotional prosody. The patient is shown a picture of a face showing some emotional state and listens to a sentence. The patient's task is to decide if the sentence was said in the way that matches the picture.

\begin{tabular}{lll}
\hline \multicolumn{1}{c}{ Emotional state } & Sentence & Intonation \\
\hline 1. Surprise & I can't believe this! & cheerful and pleasant \\
2. Boredom & This is so boring. & excited \\
3. Sadness & I'm really sad. & happy \\
4. Tiredness & I'm feeling exhausted. & tired \\
5. Fear & I'm so scared. & bored and lethargic \\
6. Happiness & I'm so happy! & happy \\
7. Confused & I don't know what to do now. & confused \\
8. Nervous & I'm so nervous! & happy \\
9. Relaxed & This is very relaxing. & slow, relaxed, content \\
10. Focused/involved & This is so interesting! & involved, enthusiastic \\
11. Disgust & This is so horrible! & cheerful and pleasant \\
12. Laughter & This is so funny! & sad \\
13. Scepticism & I don't trust these people. & sceptical \\
14. Anger & I hate you! & cheerful and pleasant \\
15. Laughter & This is so funny! & angry \\
\hline
\end{tabular}


(2) Affective prosody test 2.

This is an alternative test to Affective Prosody Test 1 without a visual input (a picture). The patient listens to sentences from the previous test and decides if the way in which they are read (intonational modulation) is compatible with the contents of the sentence (Susan Bookheimer, p.c.).

\subsection{IES tests for the subcortex}

During IES of the subcortex, the patient has to be awake during the extraction of tissue because the neurosurgeon is not navigated by the results of functional language areas obtained from non-invasive brain imaging. Therefore, a more detailed testing procedure with the patient being awake during resection is required. The functional areas of the subcortex cause the following speech disturbances during IES: (1) anomia, (2) dysarthria, (3) initiation disorders and reduction of spontaneous speech (Duffau et al. 2002).

(1) Describe your best friend.

(2) How do you like to dress?

(3) What do you like to do in your free time?

(4) What is your favourite sport?

(5) What do people do during weekends?

(6) How did you spend last summer?

(7) Which season of the year do you like the most and which do you like the least?

(8) What are the traits of character that you would like your significant other to have?

(9) Which pet is your favourite and why?

(10) Describe your daily routine.

(11) What is the most interesting place you have ever visited and why?

(12) Why are mobile phones so popular?

(13) What is your favourite TV show/book?

(14) Describe one of your family members.

(15) Describe the happiest event of your childhood.

(16) What are your plans for your next holiday?

(17) Name a few features that annoy you in other people.

(18) If you had a visitor from abroad, which places would you show them in your country?

(19) Describe your favourite holiday.

(20) Who's your favourite actor and why?

According to Berger and Rostmomily (1997), the patient may progressively become fatigued in the course of IES and tissue resection, therefore more frequent breaks which 
last a few minutes may be required. If the tests for $\mathrm{LH}$ and $\mathrm{RH}$ become too difficult for an excessively tired patient, the test on spontaneous speech can be used as a substitute test. If IES elicits disturbances in speech, the removal of tissue must be interrupted.

\subsection{Tests for patients with subdural grids}

Prior to the removal of a brain area causing epileptic seizures, patients with intractable epilepsy undergo a procedure of implanting a multielectrode subdural grid and then spend a few days with it in a ward. The role of the subdural grid is to trace the source of the patient's seizures (Engel et al. 2005). The grid consists of 3-4 mm diameter electrodes that are embedded one centimetre apart (Crone et al. 1998). It gives a chance to perform an electrical stimulation of those areas of the cortex which are covered with the grid. This type of language mapping is carried out in a ward and is not time-limited. Połczyńska (2006) emphasises that the new language tests are first used with patients with subdural grids. This is to assure maximum safety and efficiency of the tests before they are used during IES for the first time. It is hoped that results obtained with patients with the grids serve as a valuable and reliable source of information for further modifications of the new tests.

\section{Additional information}

All the patients scheduled for IES of the cortex and the subcortex will be trained to perform IES language tests to make the testing procedure as efficacious as possible.

In addition to this, prior to neurosurgical procedures, patients will be tested with a baseline language test to verify if they exhibit any deterioration of language caused by changes in areas affected by a tumour or epilepsy. This test will also be carried out within 1-3 days post-surgery and after a month.

\section{Conclusion}

IES of the brain is performed to localise and spare language functional areas before extraction of brain tissue in patients with tumors and epilepsy. The procedure is very precise and highly effective. Yet, it is argued that language tests used during IES are too limited. This article presented new language tests that have a potential of minimising post-operative risk to language function. Extended versions of previously presented tests (Połczyńska 2006), as well as new tests were presented. The IES are designed in three sets: (1) Grammar-focused language tests for the dominant left hemisphere; (2) Non-dominant right-hemisphere IES tests; and (3) Language tests for IES for the subcortex. Patients with intractable epilepsy need to undergo an additional procedure prior 
to the removal of a brain area causing epileptic seizures: an implantation of a multielectrode subdural grid onto the cortical surface of the brain to trace the source of the patient's seizures. A subdural grid gives a chance to perform an electrical stimulation of areas of the cortex under the grid. This type of language mapping is carried out in a ward and is not time-limited. It is suggested that the new language tests are first used with patients with subdural grids. This is to assure maximum safety and efficiency of the tests before they are used during IES for the first time. It is hoped that results obtained with patients with the grids serve as a valuable and reliable source of information for further modifications of the new tests. All the patients scheduled for IES will be tested with a baseline language test to verify if they exhibit any deterioration of language caused by changes in areas affected by a tumour or epilepsy. This test will also be carried out within 1-3 days post-surgery and after a month.

\section{ACKNOWLEDGEMENTS}

I would like to thank Prof. Katarzyna Dziubalska-Kołaczyk for her very strong support and involvement in the project, as well as Prof. Susan Curtiss, Prof. Itzhak Fried and Prof. Steven Small for most fruitful discussions regarding implementing this project into practice. I would also like to thank two of my B.A. students - Marta Grocholska and Katarzyna Spyra - for their fresh ideas concerning the Distant semantic relationships test A. Finally, I would like to thank two anonymous subjects who agreed to undergo the IES language tests and for their constructive comments on the tests.

\section{REFERENCES}

Arabatzi, M. and S. Edwards. 2002. "Tense and syntactic processes in agrammatic speech". Brain and Language 80. 314-327.

Benson, D.F. 1979. Aphasia, alexia and agraphia. Edinburgh: Churchill Livingston.

Baum, S. and M. Pell. 1999. "The neural bases of prosody: Insights from lesions studies and neuroimaging". Aphasiology 13. 581-608.

Beeman M. 1998. "Coarse semantic coding and discourse comprehension". In: Beeman M., and C. Chiarello (eds.), Right hemisphere language comprehension: Perspectives from cognitive neuroscience. Mahwah, NJ: Lawrence Erlbaum. 255-284.

Bello, L., F. Acerbi, C. Giussani, P. Baratta, P. Taccone, V. Songa, M. Fava, N. Stocchetti, C. Papagno, and S.M. Giaini. 2006. "Intraoperative language localisation in multilingual patients with gliomas". Neurosurgery 59. 115-125.

Berger, M.S. and R.C. Rostomily. 1997. "Low grade gliomas: Functional mapping resection strategies, extent of resection, and outcome". Journal of Neurooncology 34. 85-101.

Cappa, S.F. and G. Vallar. 1992. "Neuropsychological disorders after subcortical lesions: Implications for neural models of language and spatial attention". In: Vallar, G., S.F. Cappa and C.W. Wellesch (eds.), Neurological disorders associated with subcortical lesions. Oxford: Oxford University Press. 7-41. 
Chantraine, Y., Y. Joanette and B. Ska. 1998. "Conversational abilities in patients with right hemisphere damage". Journal of Neurolinguistics 11. 21-32.

Crone, N.E., D.L. Miglioretti, B. Gordon and R.P. Lesser. 1998. "Functional mapping of human sensorimotor cortex with electrocorticographic spectral analysis. II. Event-related synchronisaton in the gamma band". Brain 121. 2301-2315.

Crosson, B. 1992. Subcortical functions in language and memory. New York: Guilford Press.

Curtiss, S. and J. Shaeffer. 2005. "Syntactic development in children with hemispherectomy: The I-, D- and C-systems". Brain and Language 94. 147-166.

Cutica, I., M. Bucciarelli and B.B. Bara. 2006. "Neuropragmatics: Extralinguistic pragmatic ability is better preserved in left-hemisphere-damaged patients than in right-hemispheredamaged patients". Brain and Language 98. 12-25.

Damasio, A.R. 1994. Descartes' error. Emotion, reason, and the human brain. New York: Putnam.

Dara, C. and M.D. Pell. 2006. "Effect of right-hemishpere damage on explicit and implicit processing of emotional prosody”. Brain and Language 99. 51-52.

Davis, C., J.T. Kleinman, M. Newhart, L. Gingis, M. Pawlak and A.E. Hillis. 2008. "Speech and language functions that require a functioning Broca's area". Brain and Language 105. 5058.

Dogil, G. 2003. “Understanding prosody”. In: Rickheit, G., T. Hermann and W. Deutsch (eds.), Psycholinguistics: An international handbook. Berlin: Mouton de Gruyter. 522-566.

Duffau, H., L. Capell, D. Denvil, N. Sichez, P. Gatignol, L. Taillandier, M. Lopes, M.C. Mitchell, S. Roche, J.C. Muller, A. Bitar, J.P. Sichez and R. van Effenterre. 2003. "Usefulness of intraoperative subcortical mapping during surgery for low-grade gliomas located within eloquent brain regions: Functional results in a consecutive series of 103 patients". Journal of Neurosurgery 98. 764-778.

Duffau, H., L. Capelle, N. Sichez, D. Denvil, M. Lopez, J.P. Sichez, A. Bitar and D. Fohanno. 2002. "Intraoperative mapping of the subcortical language pathways using direct stimulations. An anatomo-functional study". Brain 125. 1-16.

Ebeling, U., U.D. Schmid, H. Ying and H.J. Reulen. 1992. "Safe surgery of lesions near the motor cortex using intra-operative mapping techniques: A repost on 50 patients". Acta Neurochirurgica $119.23-28$.

Engel, A.K., C.K. Moll, I. Fried and G.A. Ojemann. 2005. "Invasive recordings from the human brain: Clinical insights and beyond". Neuroscience 6. 35-47.

Fabbro, F., A. Peru and M. Skrap. 1997. "Language disorders in bilingual patients after thalamic lesions”. Journal of Neurolinguistics 10(4). 347-367.

Fournier, N.M., K.L. Calverley, J.P. Wagner, J.L. Poock and M. Crossley. 2008. "Impaired social cognition 30 years after hemispherectomy for intractable epilepsy: The importance of the right hemisphere in complex social functioning". Epilepsy and Behaviour 12(3). 460471.

Fried, I., G.A. Ojemann and E.E Fetz. 1981. "Language-related potentials specific to human language cortex". Science 212. 353-356.

Fried, I., A. Katz, G. McCarthy, K.J. Sass, P. Williamson, S.S. Spencer and D.D. Spencer. 1991. "Functional organization of human supplementary motor cortex studied by electrical stimulation". Journal of Neuroscience 11(11). 3656-3666.

Friedmann, N. and Y.Grodzinsky. 1997. "Tense and agreement in agrammatic production: Pruning the syntactic tree". Brain and Language 56. 397-425.

Haglund, M.M., M.S. Berger, M. Shamseldin, E. Lettich and G.A. Ojemann. 1994. "Cortical localisation of temporal lobe language sites in patients with gliomas". Neurosurgery 34. 567576. 
Heilman, K.M., R. Scholes and R.T. Watson. 1975. "Auditory affective agnosia. Disturbed comprehension of affective speech". Journal of Neurology, Neurosurgery and Psychiatry 38. 69-72.

Hirsch, J., M.I. Ruge and K.H.S. Kim. 2000. “An integrated functional magnetic resonance imaging procedure for preoperative mapping of cortical area associated with tactile, motor, language, and visual functions". Neurosurgery 47. 711-722.

Hughlings-Jackson, J. 1878 and 1879. "On affections of speech from diseases of the brain". (2 parts.) Brain 1. 304-330. Brain 2. 202-222.

Hunke, K., B. Van de Wiele, I. Fried and E.H. Rubinstein. "The asleep-awake-asleep anesthetic technique for intraoperative language mapping”. Neurosurgery 42(6). 1312-1317.

Kacinik, N.A. and C. Chiarello. 2007. "Understanding metaphors: Is the right hemisphere uniquely involved?" Brain and Language 100. 188-207.

Larsen, B., E. Skinhoj and N.A. Lassen. 1978. "Variations in regional cortical blood flow in the right and left hemispheres during automatic speech". Brain 101. 193-209.

Lehéricy, S., H. Duffau, P. Cornu, L. Capelle, B. Pidoux, A. Carpentier, S. Auliac, S. Clemenceau, J.P. Sichez, A. Bitar, C.A. Vallery, R. Van Effenterre, T. Faillot, A. Srour, D. Fohano, J. Philippon, D. Le Bihan and C. Marsault. 2000. "Correspondence between functional magnetic resonance imaging somatotopy and individual brain anatomy of the central region: Comparison with intraoperative stimulation in patients with brain tumors". Journal of Neurosurgery $92.589-598$.

Love, T., D. Swinney, M. Walenski and E. Zurif. 2008. "How left inferior frontal cortex participates in syntactic processing: Evidence from aphasia”. Brain and Language 107(3). 203219.

Marcus, F.M., A. Vouloumanos and I.A. Sag. 2003. “Does Broca's play by the rules?”. Nature Neuroscience 6(7). 651-653.

Mashal, N., M. Faust, T. Hendler and M. Jung-Beeman. 2007. "An fMRI investigation of the neural correlates underlying the processing of novel metaphoric expressions". Brain and Language 100. 115-126.

McDermot K.B., J.M. Watson and J.G. Ojemann. 2005. "Presurgical language mapping”. Current Directions in Psychological Science 14(6). 291-295.

Momo, K., H. Sakai and K.L. Sakai. 2008. "Syntax in a native language still continues to develop in adults: Honorification judgment in Japanese". Brain and Language 107(1). 81-89.

Musso, M., A. Moro, V. Glauche, M. Rijntjes, J. Reinbach, C. Büchell and C. Weiller. 2003. "Broca's area and the language instinct". Nature Neuroscience 6(7). 774-781.

Ojemann, G.A., J. Ojemann, E. Lettich and M. Berger. 1989. "Cortical localisation in left, dominant hemisphere. An electrical stimulation mapping investigation in 117 patients". Journal of Neurosurgery 71. 316-326.

Ojemann, G.A. 1991. "Cortical organisation of language". Journal of Neuroscience 11. 22812287.

Monetta, L., C. Oulet-Plamandon and Y. Joanette. 2006. "Stimulating the pattern of righthemisphere-damaged patients for the processing of the alternative metaphorical meanings of words: Evidence in favour of a cognitive resources hypothesis". Brain and Language 96. 171-177.

Paradis, M. 1994. "Neurolinguistic aspects of implicit and explicit memory: Implications for bilingualism”. In: Ellis, N. (ed.), Implicit and explicit learning of second languages. London: Academic Press. 393-419.

Paradis. M. 2004. A neurolonguistic theory of bilingualism. (Studies in bilingualism 18.) Amsterdam: John Benjamins. 
Połczyńska, M. 2008. "Saving language after brain surgery with language tests during intraoperative electrical stimulation and pre-operative brain mapping methods". In: Niemi, J. and S. Werner (eds), Sudies in Languages 44. Proceedings from the 1st Nordic Conference of Clinical Linguistics. Joensuu: University of Joensuu. 113-121.

Pouratian, N., S. Bookheimer, G. Rubino, A. Martin and N. Toga. 2003. "Category-specific naming deficit identified by intraoperative stimulation mapping and postoperative neuropsychological testing". Journal of Neurosurgery 99(1). 170-176.

Ross, E.D. 1981. "The aprosodias: Functional-anatomic organization of the affective components of language in the right hemisphere". Archives of Neurology 38. 561-569.

Ross, E.D., R.D. Thomson and Y.P. Yenkosky. 1997. "Lateralisation of affective prosody in brain and the callosal integration of hemispheric language functions". Brain and Language 56. 27-54.

Ross, E.D. and M. Monnot. 2008. "Neurology of affective prosody and its functional-anatomic organisation in right hemisphere". Brain and Language 104. 51-74.

Roux F.-E. and M. Trémoulet 2002. "Organisation of language in bilingual patients." Journal of Neurosurgery $97.857-864$.

Shamay-Tsoory, S.G., R. Tomer and J. Aharon-Peretz. 2005. "The neuroanatomical basis of understanding sarcasm and its relationship to social cognition". Neuropsychology 19(3). 288300.

Shamay-Tsoory, S.G., R. Tomer, B.D. Goldsher and J. Aharon-Peretz. 2004. "Impairment in cognitive and affective empathy in patients with brain lesions: Anatomical and cognitive correlates". Journal of Clinical and Experimental Neuropsychology 26(8). 1113-1127.

Sheibel, A.B., I. Fried, L. Paul, A. Forsythe, U. Tomiyasu, A. Wechsler, A. Kao and J. Slotnick. 1985. "Differentiating characteristics of the human speech cortex: A quantitative Golgi study". In: Benson, D.F. and E. Zaidel E. (eds), The dual brain. New York: Guilford Press. 65-74.

Schmidt, G.L, C.J. De Buse and C.A. Seger. 2007. "Right hemisphere metaphor processing? Characterising the lateralisation of semantic processes". Brain and Language 100. 127-141.

Stark, J.A., H.K. Stark, C. Pons and S.M. Viola. 2006. "Analysing verbal communicative behaviour of left-and right-brain lesioned clients on the ANELT". Brain and Language 99. 16-18.

Stuss, D.T., G.G. Gallup and M.P. Alexander. 2001. "The frontal lobes are necessary for 'the theory of mind"'. Brain 124. 279-286.

Taylor, M.D. and M. Bernstein. 1999. "Awake craniotomy with brain mapping as a routine surgical approach to treating patients with supratentorial intraaxial tumors: A prospective trial of 200 cases". Journal of Neurosurgery 90. 35-41.

Tomkins, C.A., V.L. Scherp, W. Fassbinder, K. Meigh and E.A. Armstrong. 2006. “"Theory of Mind' in adults with right hemisphere brain damage". Brain and Language 99. 67-68.

Van Lancker, D. 1980. "Cerebral lateralization of pitch cues in the linguistic signal". International Journal of Human Communication 11. 193-212.

Van Lancker Sidtis, D., N. Pachana, J.L. Cummings and J.J. Sidtis. 2006. "Dysprosodic speech following basal ganglia insult: Toward a conceptual framework for the study of the cerebral representation of prosody". Brain and Language 97. 135-153.

Vinas, F.C., L. Zamorano, R.A. Muller, Z. Jiang, H.T. Chugani, D. Fuerst, O. Muzik, T.J. Mangner and F. Diaz. 1997. "[150]-water PET intraoperative brain mapping: A comparison in the localization of eloquent cortex". Neurological Research 19. 601-608.

Weems, S.A. and E. Zaidel. 2005. "Repetition priming within and between the two cerebral hemispheres". Brain and Language 93. 298-307. 
Wise, R., F. Chollet, U. Hadar, K. Friston, E. Hoffner and R. Frackowiack. 1991. "Distribution of cortical neural networks involved in word comprehension and word retrieval". Brain 114. $1803-1817$.

\section{Address correspondence to:}

Monika Połczyńska

School of English

Adam Mickiewicz University

al. Niepodległości 4

61-874 Poznań

Poland

plmonik@ifa.amu.edu.pl 